\title{
A Network Meta-analysis Comparing Exenatide Once Weekly with Other GLP-1 Receptor Agonists for the Treatment of Type 2 Diabetes Mellitus
}

\author{
Sheena Kayaniyil · Greta Lozano-Ortega · Heather A. Bennett • \\ Kristina Johnsson · Alka Shaunik · Susan Grandy · Bernt Kartman
}

To view enhanced content go to www.diabetestherapy-open.com Received: December 17, 2015 / Published online: February 17, 2016

(C) The Author(s) 2016. This article is published with open access at Springerlink.com

\section{ABSTRACT}

Introduction: Exenatide is a glucagon-like peptide-1 receptor agonist (GLP-1 RA), approved for treatment of type 2 diabetes mellitus (T2DM). There is limited direct evidence comparing the efficacy and tolerability of exenatide $2 \mathrm{mg}$ once weekly (QW) to other GLP-1 RAs. A network meta-analysis (NMA) was conducted to estimate the relative efficacy and tolerability of exenatide QW versus other GLP-1 RAs for the

Electronic supplementary material The online version of this article (doi:10.1007/s13300-016-0155-1) contains supplementary material, which is available to authorized users.

S. Kayaniyil $(\bowtie) \cdot$ H. A. Bennett

ICON Health Economics and Epidemiology,

Toronto, ON, Canada

e-mail: sheena.kayaniyil@iconplc.com

\section{G. Lozano-Ortega}

ICON Health Economics and Epidemiology,

Vancouver, BC, Canada

K. Johnsson · B. Kartman

AstraZeneca, Mölndal, Sweden

A. Shaunik · S. Grandy

AstraZeneca, Gaithersburg, MD, USA treatment of adults with T2DM inadequately controlled on metformin monotherapy.

Methods: A systematic literature review was conducted to identify randomized controlled trials (RCTs) that investigated GLP-1 RAs (albiglutide, dulaglutide, exenatide, liraglutide, and lixisenatide) at approved doses in the United States/Europe, added on to metformin only and of $24 \pm 6$ weeks treatment duration. A Bayesian NMA was conducted.

Results: Fourteen RCTs were included in the NMA. Exenatide QW obtained a statistically significant reduction in glycated hemoglobin (HbA1c) relative to lixisenatide $20 \mu \mathrm{g}$ once daily. No other comparisons of exenatide QW to other GLP-1 RAs were statistically significant for change in HbA1c. No statistically significant differences in change in weight, systolic blood pressure, risk of nausea or discontinuation due to adverse events were observed for exenatide QW versus other GLP-1 RAs.

Conclusion: Exenatide QW demonstrated similar effectiveness and tolerability compared to other GLP-1 RAs, for the treatment of T2DM in adults inadequately controlled on metformin alone. 
Keywords: Exenatide once weekly; GLP-1 receptor agonist; Network meta-analysis; Type 2 diabetes

\section{INTRODUCTION}

Achieving and maintaining glycemic control is the primary goal in the management of type 2 diabetes mellitus (T2DM). Patients are encouraged to adopt a healthy diet and increase their exercise; however, for patients who do not achieve glycemic control following lifestyle changes, oral antidiabetic agents are typically prescribed. Therapy is initiated with metformin, and other agents are added to the treatment regimen as necessary, to achieve the desired level of glycemic control [1]. Glucagon-like peptide-1 receptor agonists (GLP-1 RAs) are a class of glucose-lowering agents used in the treatment of T2DM. The addition of a GLP-1 RA is one of the recommended injectable approaches for patients who are inadequately controlled on metformin monotherapy [1].

Exenatide is a GLP-1 RA approved for the management of glycemic control among individuals with $\mathrm{T} 2 \mathrm{DM}$ and is currently marketed in two formulations: a solution for twice-daily injection providing either 5 or $10 \mu \mathrm{g}$ of exenatide [exenatide twice daily (BID)] and a prolonged-release once weekly (QW) injection that provides $2 \mathrm{mg}$ of exenatide (exenatide QW). The long-acting formulation contains the active ingredient of the original exenatide BID formulation dispersed in microspheres of medical-grade poly-(d,l-lactide-co-glycolide) in an aqueous formulation [2]. Exenatide BID was the first GLP-1 RA approved in the twice-daily formulation, and exenatide QW was the first GLP-1 RA approved in the once weekly setting [3]. Other GLP-1 RAs administered QW that have since been developed include albiglutide and dulaglutide, whereas liraglutide and lixisenatide are administered once daily (QD). Overall, there are now several GLP-1 RAs on the market, with different dosing, and some evidence suggestive of differences in potencies [4-6]. Exenatide QW is expected to be associated with greater adherence and compliance than daily dosing, which could in turn translate into increased efficacy. As such, a study that estimates the relative efficacy and tolerability of exenatide QW compared to the existing GLP-1 RAs that have been developed is needed and would be valuable to investigate.

The efficacy and tolerability of exenatide in its QW formulation has been demonstrated in randomized controlled trials (RCT) within the DURATION clinical trial program [7-10] and real-world evidence studies [11-13]. Apart from the direct comparison of exenatide QW to $\begin{array}{lll}\text { exenatide } & \text { BID } & \text { [DURATION }\end{array}$ (ClinicalTrials.gov identifier, NCT00308139) and DURATION-5 (ClinicalTrials.gov identifier, NCT00877890) trials] [7-9], there was one other trial [DURATION-6 trial (ClinicalTrials.gov identifier, NCT01029886)] where exenatide QW was directly compared to another GLP-1 RA [10]. In the DURATION-6 trial, the efficacy and safety of exenatide QW was compared to liraglutide $1.8 \mathrm{mg}$ QD in patients with T2DM treatment with lifestyle modification and one or more oral antihyperglycemic agents [10]. Newer GLP-1 RAs (albiglutide, dulaglutide and lixisenatide) have not been compared directly to exenatide QW.

In the absence of head-to-head evidence within a clinical trial setting, the efficacy and tolerability of exenatide $2 \mathrm{mg} \mathrm{QW}$, relative to other GLP-1 RAs, can be estimated using both direct and indirect evidence within a network meta-analysis (NMA) [14, 15]. Where limited 
direct evidence does exist, NMAs allow pooling direct and indirect evidence together in a single analysis. The technique is based on the assumption that, on a suitable scale, one can add and subtract the within-trial estimates of relative treatment effects to obtain indirect evidence. In this case, the difference in effect between treatments $\mathrm{A}$ and $\mathrm{B}$ equals the difference in effects between treatments $A$ and $\mathrm{C}$ and $\mathrm{B}$ and $\mathrm{C}[14,16]$.

The objective of this study was to estimate the relative clinical efficacy and tolerability of exenatide QW, compared to GLP-1 RAs approved in the US and/or Europe, for the treatment of T2DM for patients who fail to achieve glycemic control on metformin monotherapy. Efficacy outcomes considered were mean change from baseline for glycated hemoglobin $\left(\mathrm{HbA}_{1 \mathrm{c}}\right) \quad(\%)$, weight $(\mathrm{kg})$ and systolic blood pressure (SBP) (mmHg) and proportion of patients achieving glycemic target (HbA1c $<7 \%$ and $\leq 7 \%$ ) at $24 \pm 6$ weeks. Tolerability was considered by estimating the relative odds of experiencing nausea or of treatment discontinuation due to any adverse event.

\section{METHODS}

\section{Identification of Trials}

A systematic literature review (SLR) was conducted to identify RCTs to inform the NMA. EMBASE, MEDLINE, and the Cochrane Central Register of Controlled Trials were searched from database inception to October 2014. PubMed was searched from August to October 2014, to identify new studies not indexed in EMBASE/MEDLINE. Conference abstracts from the European Association of the Study of Diabetes (EASD) 49th Annual Meeting (2013), and the American Diabetes Association
(ADA) 73rd (2013) and 74th (2014) Scientific Sessions were searched to identify studies ahead of full publication. Full search syntax is available in the supplementary material (Table S1). All searches were limited to English language publications.

RCTs suitable for inclusion in the review were selected using strict predefined inclusion/ exclusion criteria based on the population, intervention, comparators, outcomes and study design (PICOS) approach recommended by the Cochrane Collaboration [17]. Key inclusion criteria were as follows: RCTs that examined the use of GLP-1 RAs at doses approved in the US and/or Europe for the treatment of T2DM (albiglutide $30 \mathrm{mg}$ QW, albiglutide $50 \mathrm{mg}$ QW, dulaglutide $0.75 \mathrm{mg}$ QW, dulaglutide $1.5 \mathrm{mg}$ QW, exenatide $5 \mu \mathrm{g}$ BID, exenatide $10 \mu \mathrm{g}$ BID, exenatide $2 \mathrm{mg}$ QW, liraglutide $1.2 \mathrm{mg} \mathrm{QD}$, liraglutide $1.8 \mathrm{mg} \mathrm{QD}$, or lixisenatide $20 \mu \mathrm{g}$ QD), each as add-on therapy to metformin monotherapy only, for the treatment of T2DM, in adults (aged over 18 years) who had inadequately controlled glycemia following treatment with metformin monotherapy. Outcomes were to be reported at $24 \pm 6$ weeks. This time period was deemed long enough to capture all outcomes of interest and allow for the inclusion of the largest body of evidence. Longer duration studies which reported outcomes at $24 \pm 6$ weeks were also eligible for inclusion in the review. Key exclusion criteria were as follows: RCTs that specifically examined patients with renal impairment, involved monotherapy treatment only, or where change in body weight was the primary outcome.

The GLP-1 RA clinical programs differed largely in terms of background medications allowed during the trial and patients previous use of antidiabetic agents. To minimize heterogeneity of the population included in 
the NMA, to account for different efficacies of various antihyperglycemic agents [18-20], and to ensure similarity regarding the population's clinical spectrum of T2DM, at least $80 \%$ of patients in each treatment arm within an eligible trial must have received background therapy consisting only of metformin monotherapy during the trial; and at least $80 \%$ of patients in all treatment arms within the trial must have metformin monotherapy or diet and exercise as the pre-trial diabetes management method.

Two reviewers independently determined whether articles met inclusion criteria. Abstracts of all identified articles were first assessed by each reviewer. Full text articles were obtained for any articles where inclusion could not be determined from the abstract alone. Discrepancies between reviewers were resolved by consensus-a third reviewer adjudicated unresolved disputes; the judgment of the third reviewer was considered final. Data extraction was performed by one analyst who extracted data elements from each included RCT, and line verification of the extraction fields was performed by a second reviewer. Discrepancies between reviewers were resolved as described above.

The Cochrane Collaboration's tool for assessing risk of bias [21] was used to assess the quality of the included RCTs. Two reviewers independently assessed the quality of included studies. A third party resolved disagreement in the manner as described for study selection.

\section{Statistical Methods}

Mean values and associated measures of variability [variance, standard deviation, standard error (SE) or confidence interval (CI)] were extracted for continuous endpoints. Where measures of variability were not reported, the SE was imputed by borrowing information from other studies included in the review, using methods recommended by the Cochrane handbook for systematic reviews of interventions [17]. Counts or proportion of events was extracted for binary endpoints. Statistical analyses, other than the NMA were conducted using the statistical package Stata 12 (StataCorp, College Station, Texas, US).

The NMA was fitted by Markov Chain Monte Carlo techniques using the statistical package WinBUGS, version 1.4.3. (Cambridge, United Kingdom) [22] Code for the NMA was based on that recommended by the National Institute for Health and Clinical Excellence Decision Support Unit [23]. Non-informative (or "vague") prior distributions were used to ensure estimates of treatment effects were informed by the trial data rather than by the choice of prior distribution.

For each outcome, random effects (RE) and fixed effect (FE) models were run. The a priori choice of model was an RE model, based on the assumption that there is not one true effect. A FE model was selected over an RE model by making considerations of the following aspects: (1) model fit among the FE and RE models, based on the deviance information criteria (DIC), which quantifies the trade-off between the goodness of fit of the data to the model and the complexity of the model, with a lower DIC value indicating a better fit; and (2) whether the posterior distribution of the between-studies variance was updated from the prior distribution with reasonable precision (i.e., credible interval (CrI) around between-studies variance was narrow enough that results from the RE model were still informative). If the between-studies variance was not appropriately updated, particularly because of having a sparse network of evidence (i.e., model was unable to estimate this parameter with the available 
evidence base), the FE model was selected over the RE model, when DIC values were comparable. However, in these cases, it is encouraged to look at results from both the FE and RE model and understand that the true value is likely between these findings.

Meta-regressions were conducted to explore heterogeneity in treatment effects due to differences in baseline values. These models were not deemed robust, as there were not enough data points informing the covariate effect (i.e., comparisons against the reference treatment informed by more than one study). The results from these models are hence not presented. Mean changes in $\mathrm{HbA}_{1 \mathrm{c}}$, weight, and SBP were analyzed using the mean difference scale; proportion of subjects achieving glycemic target, proportion of subjects experiencing nausea or who discontinued due to adverse events were analyzed on an odds ratio scale. Key elements of patient population and baseline risk were summarized in boxplots, to evaluate heterogeneity in the network $[16,24]$.

Each model was coded, analyzed, summarized using graphical and summary tables, validated, and reported. Model convergence was checked by examining caterpillar and density plots. The NMA presents results for GLP-1 RAs included in the network; antihyperglycemic agents that provided indirect evidence were not considered agents of interest and results for those agents are not presented.

For studies that presented endpoints in graph format only, values were derived by digitizing the graph, using the DigitizeIt program, version 1.5 (DigitizeIt, Braunschweig, Germany). Endpoints reported at week 24 were preferred, but data were acceptable if reported between 18 and 30 weeks post-randomization.

To generate estimates on the absolute scale, the mean reported absolute effect across the included placebo arms within each network was calculated and used as the anchor point (liraglutide $1.2 \mathrm{mg}$ QD was used for the SBP network). These anchor values were then added to the relative treatment effects estimated by the NMA.

\section{Compliance with Ethics Guidelines}

This article is based on previously conducted studies, and does not involve any new studies of human or animal subjects performed by any of the authors.

\section{RESULTS}

\section{Supporting Evidence}

The SLR identified 662 articles of which 14 RCTs met criteria for inclusion in the NMA [25-38]. A PRISMA flow chart summarizing search results and study selection is provided in the supplementary material (Figure S1 in the supplementary material). Table 1 presents study and patient characteristics from the 14 RCTs included in the NMA.

The mean age of participants ranged from 42.7 to 58.2 years, average duration of T2DM ranged from 4.4 to 8.2 years, and baseline $\mathrm{HbA} 1 \mathrm{c}$ ranged from $7.8 \%$ to $8.9 \%$. Boxplots for mean age, duration of T2DM, HbA1c and weight at baseline, by treatment comparators, are presented in the supplementary material (Figure S2).

The overall quality of the included trials in the network was good. The generation of the randomization sequence and concealment of blinding was adequate, when reported; however, this was not always described by authors. Eight studies were open-label, as this design is often used for drugs with injections, and for therapeutic monitoring. Most of the studies reported similar characteristics between 


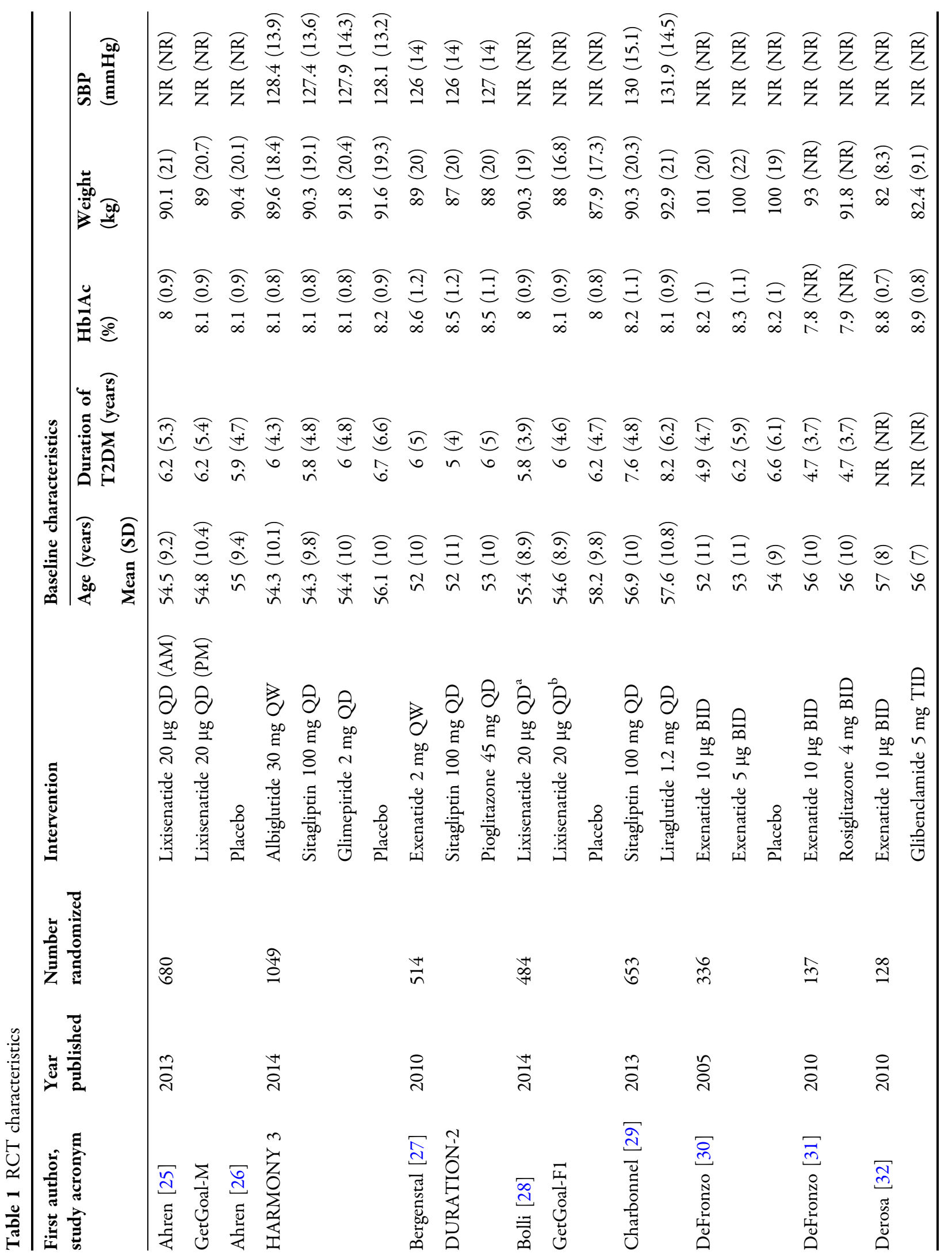




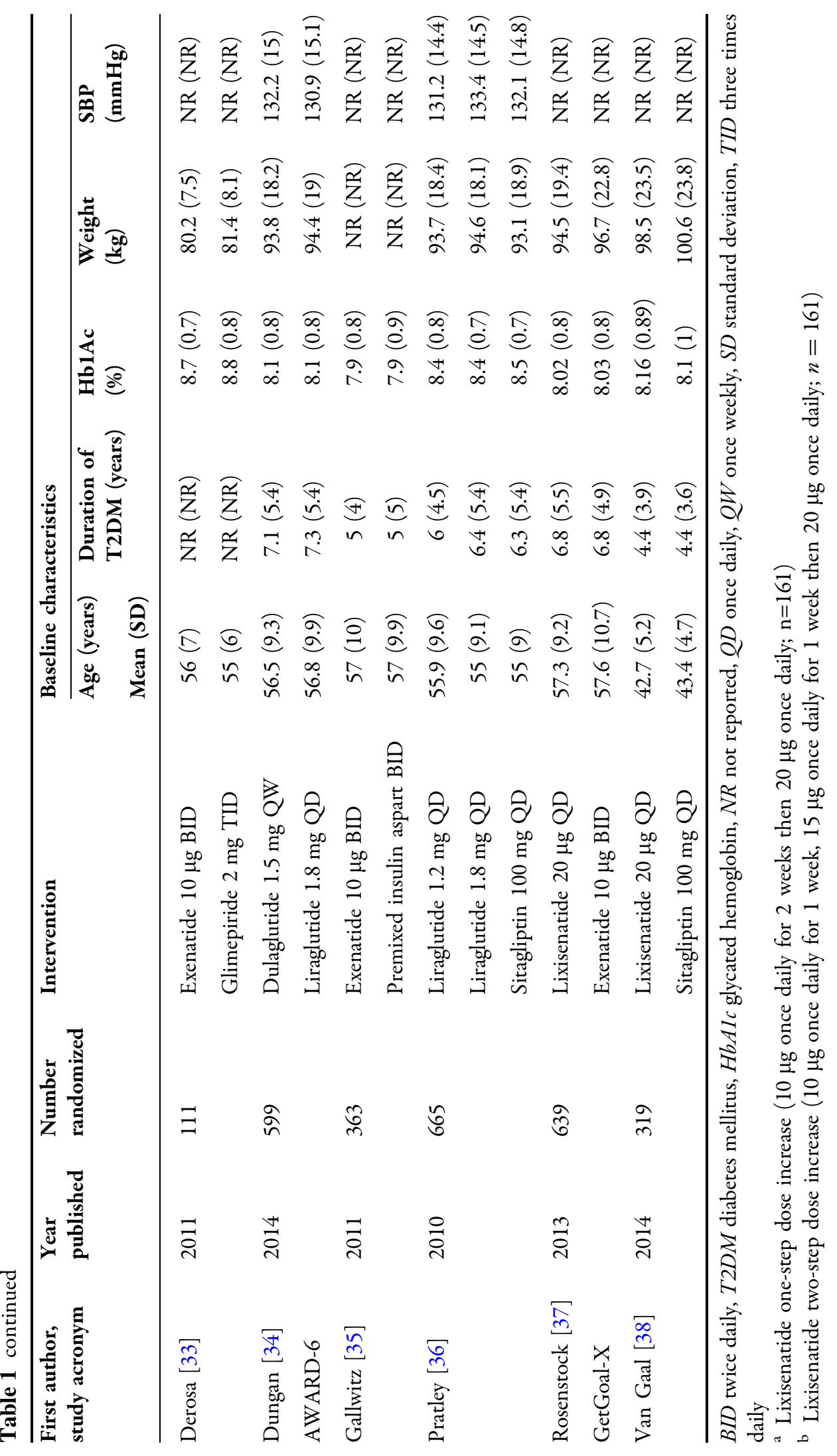


Table 2 Relative effect sizes for mean change in $\mathrm{HbA}_{1 \mathrm{c}}$

\begin{tabular}{|c|c|c|c|c|}
\hline \multirow[t]{3}{*}{ Regimen } & \multicolumn{4}{|c|}{ Change in HbAlc from baseline (\%) } \\
\hline & \multicolumn{2}{|l|}{ Random effects model } & \multicolumn{2}{|l|}{ Fixed effect model } \\
\hline & $\begin{array}{l}\text { All vs. placebo } \\
\text { Mean }(95 \% \text { CrI })\end{array}$ & $\begin{array}{l}\text { Exenatide QW vs. all } \\
\text { Mean }(95 \% \mathrm{CrI})\end{array}$ & $\begin{array}{l}\text { All vs. Placebo } \\
\text { Mean }(95 \% \text { CrI })\end{array}$ & $\begin{array}{l}\text { Exenatide QW vs. all } \\
\text { Mean }(95 \% \mathrm{CrI})\end{array}$ \\
\hline Placebo & $\mathrm{N} / \mathrm{A}$ & $-1.09(-1.65,-0.53)^{*}$ & $\mathrm{~N} / \mathrm{A}$ & $-1.19(-1.52,-0.85)^{*}$ \\
\hline Dulaglutide $1.5 \mathrm{mg} \mathrm{QW}$ & $-1.09(-1.75,-0.43)^{*}$ & $0.00(-0.72,0.72)$ & $-1.19(-1.50,-0.87)^{*}$ & $0.00(-0.33,0.33)$ \\
\hline Liraglutide 1.8 mg QD & $-1.03(-1.55,-0.51)^{*}$ & $-0.06(-0.65,0.54)$ & $-1.13(-1.41,-0.84)^{*}$ & $-0.06(-0.36,0.24)$ \\
\hline Exenatide $10 \mu \mathrm{g}$ BID & $-0.75(-1.11,-0.43)^{*}$ & $-0.34(-0.95,0.31)$ & $-0.79(-0.98,-0.61)^{*}$ & $-0.39(-0.73,-0.06)^{*}$ \\
\hline Liraglutide 1.2 mg QD & $-0.71(-1.16,-0.26)^{*}$ & $-0.38(-0.92,0.16)$ & $-0.81(-1.07,-0.55)^{*}$ & $-0.38(-0.66,-0.10)^{*}$ \\
\hline Albiglutide 30 mg QW & $-0.69(-1.11,-0.28)^{*}$ & $-0.39(-1.00,0.20)$ & $-0.79(-1.04,-0.55)^{*}$ & $-0.39(-0.69,-0.10)^{*}$ \\
\hline Lixisenatide $20 \mu \mathrm{g}$ QD & $-0.50(-0.75,-0.25)^{*}$ & $-0.59(-1.15,-0.03)^{*}$ & $-0.62(-0.81,-0.42)^{*}$ & $-0.57(-0.89,-0.25)^{*}$ \\
\hline Exenatide $5 \mu \mathrm{g}$ BID & $-0.42(-0.87,0.00)^{*}$ & $-0.66(-1.35,0.05)$ & $-0.40(-0.65,-0.15)^{*}$ & $-0.79(-1.20,-0.37)^{*}$ \\
\hline Exenatide $2 \mathrm{mg} \mathrm{QW}$ & $-1.09(-1.65,-0.53)^{*}$ & $\mathrm{~N} / \mathrm{A}$ & $-1.19(-1.52,-0.85)^{*}$ & $\mathrm{~N} / \mathrm{A}$ \\
\hline
\end{tabular}

$B I D$ twice daily, $C r I$ credible interval, $H b A I c$ glycated hemoglobin, $N / A$ not applicable, $Q D$ once daily, $Q W$ once weekly

${ }^{*}$ Statistically significant difference

treatment groups at baseline. Only two studies $[25,38]$ noted differences in gender proportions at baseline between treatment groups, but significance was not tested.

The endpoint data for the individual trials included in the NMA is presented in the supplementary material; Table S2 (HbA1c, weight and SBP), Table S3 (proportion of patients achieving glycemic target), and Table S4 (tolerability data).

\section{NMA}

Characteristics of model fit for all outcomes included in the NMA are presented in the supplementary material (Table S5).

All 14 trials provided evidence for the network of mean change in $\mathrm{HbA}_{1 \mathrm{c}}$ from baseline (Figure S3 in the supplementary material). The relative effect sizes are presented in Table 2. All regimens performed significantly better than placebo at reducing HbA1c levels; point estimates varied from
$-0.42 \%$ for exenatide $5 \mu \mathrm{g}$ BID to $-1.09 \%$ for exenatide QW and dulaglutide $1.5 \mathrm{mg}$ QW. For the comparisons of exenatide QW against other active agents for the HbA1c endpoint, exenatide QW was significantly better than lixisenatide $20 \mu \mathrm{g}$ QD (mean $-0.59 \%$, 95\% CrI -1.15, -0.03). The remaining comparisons of exenatide QW to the other GLP-1 RAs were not statistically different for HbA1c change.

Ten trials reported the proportion of subjects achieving glycemic target and definitions described as HbA1c $<7 \%$ and $\leq 7 \%$ were considered for analysis (Figure S4 in the supplementary material). There were no statistically significant differences observed for exenatide QW versus the other GLP-1 RAs (Table 3).

All 14 included RCTs provided evidence for the network of mean change in weight from baseline (Figure S5 in the supplementary material). All GLP-1 RA treatment arms were associated with a reduction in weight from 
Table 3 Relative effect sizes for odds of achieving glycemic target

\begin{tabular}{|c|c|c|c|c|}
\hline \multirow[t]{3}{*}{ Regimen } & \multicolumn{4}{|c|}{ Odds of achieving glycemic target $(\leq 7 \%)$} \\
\hline & \multicolumn{2}{|l|}{ Random effects model } & \multicolumn{2}{|l|}{ Fixed effect model } \\
\hline & $\begin{array}{l}\text { All vs. placebo } \\
\text { Odds ratio } \\
(95 \% \mathrm{CrI})\end{array}$ & $\begin{array}{l}\text { Exenatide } Q W \text { vs. all } \\
\text { Odds ratio } \\
(95 \% \mathrm{CrI})\end{array}$ & $\begin{array}{l}\text { All vs. placebo } \\
\text { Odds ratio } \\
(95 \% \mathrm{CrI})\end{array}$ & $\begin{array}{l}\text { Exenatide QW vs. all } \\
\text { Odds ratio } \\
(95 \% \mathrm{CrI})\end{array}$ \\
\hline Placebo & $\mathrm{N} / \mathrm{A}$ & $7.92(0.76,85.71)$ & $\mathrm{N} / \mathrm{A}$ & $7.68(3.86,15.44)^{*}$ \\
\hline Dulaglutide $1.5 \mathrm{mg} \mathrm{QW}$ & $10.55(0.68,174.34)$ & $0.75(0.06,9.88)$ & $9.96(4.80,20.74)^{*}$ & $0.77(0.39,1.53)$ \\
\hline Liraglutide 1.8 mg QD & $10.38(1.06,108.20)^{*}$ & $0.76(0.10,6.02)$ & $9.82(5.17,18.65)^{*}$ & $0.78(0.44,1.41)$ \\
\hline Liraglutide $1.2 \mathrm{mg}$ QD & $5.76(0.70,49.75)$ & $1.38(0.21,8.95)$ & $5.48(3.03,9.94)^{*}$ & $1.40(0.83,2.38)$ \\
\hline Exenatide $10 \mu \mathrm{g}$ BID & $3.75(1.19,13.71)^{*}$ & $2.11(0.17,23.71)$ & $3.27(2.28,4.74)^{*}$ & $2.35(1.17,4.73)^{*}$ \\
\hline Lixisenatide $20 \mu \mathrm{g}$ QD & $2.91(1.12,7.83)^{*}$ & $2.72(0.31,23.43)$ & $2.82(2.14,3.74)^{*}$ & $2.72(1.44,5.16)^{*}$ \\
\hline Exenatide $5 \mu \mathrm{g}$ BID & $2.45(0.57,12.07)$ & $3.23(0.21,46.76)$ & $2.16(1.19,3.89)^{*}$ & $3.56(1.50,8.50)^{*}$ \\
\hline Exenatide $2 \mathrm{mg} \mathrm{QW}$ & $7.92(0.76,85.71)$ & $\mathrm{N} / \mathrm{A}$ & $7.68(3.86,15.44)^{*}$ & $\mathrm{~N} / \mathrm{A}$ \\
\hline
\end{tabular}

$B I D$ twice daily, $C r I$ credible interval, $N / A$ not applicable, $Q D$ once daily, $Q W$ once weekly

* Statistically significant difference

Table 4 Relative effect sizes for mean change in weight $(\mathrm{kg})$

\begin{tabular}{|c|c|c|c|c|}
\hline \multirow[t]{3}{*}{ Regimen } & \multicolumn{4}{|c|}{ Change in weight from baseline $(\mathrm{kg})$} \\
\hline & \multicolumn{2}{|l|}{ Random effects model } & \multicolumn{2}{|l|}{ Fixed effect model } \\
\hline & $\begin{array}{l}\text { All vs. placebo } \\
\text { Mean (95\% CrI) }\end{array}$ & $\begin{array}{l}\text { Exenatide } \\
\text { QW vs. all } \\
\text { Mean }(95 \% \mathrm{CrI})\end{array}$ & $\begin{array}{l}\text { All vs. placebo } \\
\text { Mean (95\% CrI) }\end{array}$ & $\begin{array}{l}\text { Exenatide } \\
\text { QW vs. all } \\
\text { Mean }(95 \% \mathrm{CrI})\end{array}$ \\
\hline Placebo & $\mathrm{N} / \mathrm{A}$ & $-1.00(-3.48,1.33)$ & $\mathrm{N} / \mathrm{A}$ & $-0.89(-2.19,0.40)$ \\
\hline Exenatide $10 \mu \mathrm{g}$ BID & $-2.05(-3.48,-0.83)^{*}$ & $1.05(-1.50,3.64)$ & $-1.92(-2.58,-1.25)^{*}$ & $1.03(-0.31,2.35)$ \\
\hline Liraglutide 1.8 mg QD & $-2.05(-4.41,0.16)$ & $1.06(-1.24,3.31)$ & $-1.97(-3.14,-0.80)^{*}$ & $1.08(-0.05,2.21)$ \\
\hline Liraglutide $1.2 \mathrm{mg}$ QD & $-1.68(-3.79,0.31)$ & $0.68(-1.38,2.70)$ & $-1.60(-2.65,-0.55)^{*}$ & $0.71(-0.30,1.71)$ \\
\hline Dulaglutide $1.5 \mathrm{mg} \mathrm{QW}$ & $-1.34(-4.17,1.37)$ & $0.35(-2.43,3.10)$ & $-1.26(-2.57,0.06)$ & $0.37(-0.92,1.65)$ \\
\hline Exenatide $5 \mu \mathrm{g}$ BID & $-1.15(-2.80,0.48)$ & $0.15(-2.77,2.92)$ & $-1.15(-2.09,-0.19)^{*}$ & $0.25(-1.33,1.83)$ \\
\hline Lixisenatide $20 \mu \mathrm{g}$ QD & $-0.80(-1.87,0.15)$ & $-0.20(-2.49,2.03)$ & $-0.71(-1.20,-0.23)^{*}$ & $-0.18(-1.38,1.03)$ \\
\hline Albiglutide $30 \mathrm{mg} \mathrm{QW}$ & $-0.20(-3.49,3.00)$ & $-0.80(-4.25,2.65)$ & $-0.11(-2.93,2.72)$ & $-0.78(-3.67,2.09)$ \\
\hline Exenatide $2 \mathrm{mg} \mathrm{QW}$ & $-1.00(-3.48,1.33)$ & $\mathrm{N} / \mathrm{A}$ & $-0.89(-2.19,0.40)$ & $\mathrm{N} / \mathrm{A}$ \\
\hline
\end{tabular}

$B I D$ twice daily, $C r I$ credible interval, $N / A$ not applicable, $Q D$ once daily, $Q W$ once weekly

* Statistically significant difference

baseline (absolute change). Only exenatide $10 \mu \mathrm{g}$ BID was significantly better than placebo in weight change from baseline (Table 4). There was no statistically significant difference in weight change between exenatide QW and the other GLP-1 RAs. 
Table 5 Relative effect sizes from the fixed effect model for mean change in systolic blood pressure $(\mathrm{mmHg})$

\begin{tabular}{|c|c|c|}
\hline \multirow{3}{*}{ Regimen } & \multicolumn{2}{|c|}{ Change in SBP from baseline $(\mathrm{mmHg})$} \\
\hline & \multicolumn{2}{|l|}{ Fixed effect model } \\
\hline & $\begin{array}{l}\text { All vs. liraglutide } 1.2 \mathrm{mg} \text { QD } \\
\text { Mean }(95 \% \mathrm{CrI})\end{array}$ & $\begin{array}{l}\text { Exenatide QW vs. all } \\
\text { Mean }(95 \% \mathrm{CrI})\end{array}$ \\
\hline Liraglutide $1.2 \mathrm{mg}$ QD & $\mathrm{N} / \mathrm{A}$ & $-2.13(-5.22,0.96)$ \\
\hline Dulaglutide $1.5 \mathrm{mg} \mathrm{QW}$ & $0.27(-2.72,3.25)$ & $-2.40(-6.41,1.62)$ \\
\hline Liraglutide $1.8 \mathrm{mg}$ QD & $0.81(-1.46,3.08)$ & $-2.94(-6.45,0.58)$ \\
\hline Exenatide $2 \mathrm{mg} \mathrm{QW}$ & $-2.13(-5.22,0.96)$ & $\mathrm{N} / \mathrm{A}$ \\
\hline
\end{tabular}

$C r I$ credible interval, $N / A$ not applicable, $Q D$ once daily, $Q W$ once weekly, $S B P$ systolic blood pressure

* Statistically significant difference. Note: the random effects model is not reported as there was not enough information to estimate the between-study standard deviation

A total of five trials provided evidence for mean change in SBP from baseline, for the following regimens: exenatide QW, dulaglutide $1.5 \mathrm{mg}$ QW, and liraglutide 1.2 and $1.8 \mathrm{mg}$ QD (Figure $\mathrm{S} 6$ in the supplementary material). The Get-Goal X trial [37], which evaluated exenatide $10 \mu \mathrm{g}$ BID vs. lixisenatide $20 \mu \mathrm{g}$ QD had to be excluded, as these agents were disconnected from the rest of the network (i.e., no direct comparisons were available between either exenatide $10 \mu \mathrm{g}$ BID or lixisenatide $20 \mu \mathrm{g}$ QD versus any of the other agents). None of the trials that reported change in SBP included a placebo arm, so liraglutide $1.2 \mathrm{mg}$ QD was chosen as the reference treatment. Exenatide QW demonstrated a trend towards greater SBP reduction against all other GLP-1 RAs in the network, although these comparisons did not achieve statistically significant results (Table 5).

A total of 11 RCTs reported nausea as an adverse event, but one trial by Gallwitz et al. [35] was excluded as information on this outcome was only provided in one treatment arm (Figure S7 in the supplementary material). Exenatide QW exhibited a trend towards a lower risk of nausea compared to all GLP-1 RAs except exenatide $5 \mu \mathrm{g}$ BID, but results were not statistically significant (point estimates of the odds ratios ranged from 0.29 vs. dulaglutide $1.5 \mathrm{mg}$ QW, to 0.98 vs. lixisenatide $20 \mu \mathrm{g}$ QD; and 1.73 for the comparison against exenatide $5 \mu \mathrm{g}$ BID) (Table 6).

Thirteen RCTs reported the number of subjects discontinuing treatment due to adverse events (Figure S8 in the supplementary material). The endpoint estimate for risk of discontinuation due to adverse events indicated a beneficial effect for exenatide QW compared to dulaglutide $1.5 \mathrm{mg} \mathrm{QW}$, and liraglutide $1.2 \mathrm{mg}$ and $1.8 \mathrm{mg} \mathrm{QD}$, but none of these differences were statistically significant (Table 7).

Estimates on the absolute scale are presented in the supplementary material (Table S6).

\section{DISCUSSION}

The position statement of the ADA and the EASD recommends the addition of GLP-1 RAs as a therapeutic option for patients with T2DM who are inadequately controlled on metformin monotherapy, with consideration of individual patient-related factors [1]. This study presents the results of an NMA that investigated the relative efficacy and tolerability of GLP-1 RAs, and in particular examined how exenatide QW, 
Table 6 Relative effect sizes for risk of nausea

\begin{tabular}{|c|c|c|c|c|}
\hline \multirow[t]{3}{*}{ Regimen } & \multicolumn{4}{|l|}{ Risk of nausea } \\
\hline & \multicolumn{2}{|l|}{ Random effects model } & \multicolumn{2}{|l|}{ Fixed effect model } \\
\hline & $\begin{array}{l}\text { All vs. placebo } \\
\text { Odds ratio } \\
(95 \% \mathrm{CrI})\end{array}$ & $\begin{array}{l}\text { Exenatide } Q W \text { vs. all } \\
\text { Odds ratio } \\
(95 \% \mathrm{CrI})\end{array}$ & $\begin{array}{l}\text { All vs. placebo } \\
\text { Odds ratio } \\
(95 \% \mathrm{CrI})\end{array}$ & $\begin{array}{l}\text { Exenatide } Q W \text { vs. all } \\
\text { Odds ratio } \\
(95 \% \mathrm{CrI})\end{array}$ \\
\hline Placebo & $\mathrm{N} / \mathrm{A}$ & $4.37(0.06,361.04)$ & $\mathrm{N} / \mathrm{A}$ & $3.77(1.35,10.69)^{*}$ \\
\hline Exenatide $5 \mu \mathrm{g}$ BID & $2.53(0.18,36.05)$ & $1.73(0.01,246.66)$ & $2.82(1.62,4.96)^{*}$ & $1.33(0.43,4.11)$ \\
\hline Lixisenatide $20 \mu \mathrm{g}$ QD & $4.45(0.78,27.49)$ & $0.98(0.02,52.67)$ & $3.86(2.69,5.61)^{*}$ & $0.98(0.37,2.61)$ \\
\hline Exenatide $10 \mu \mathrm{g}$ BID & $4.69(0.54,40.69)$ & $0.93(0.01,86.57)$ & $5.22(3.48,7.92)^{*}$ & $0.72(0.26,2.01)$ \\
\hline Liraglutide $1.2 \mathrm{mg}$ QD & $9.89(0.21,490.78)$ & $0.44(0.01,13.72)$ & $8.50(3.19,22.22)^{*}$ & $0.44(0.20,1.00)$ \\
\hline Liraglutide 1.8 mg QD & $12.96(0.18,975.55)$ & $0.34(0.01,15.75)$ & $11.60(4.17,31.79)^{*}$ & $0.32(0.14,0.77)^{*}$ \\
\hline Dulaglutide $1.5 \mathrm{mg}$ QW & $15.13(0.09,2563.17)$ & $0.29(0.00,33.99)$ & $13.56(4.52,40.37)^{*}$ & $0.28(0.11,0.73)^{*}$ \\
\hline Exenatide $2 \mathrm{mg} \mathrm{QW}$ & $4.37(0.06,361.04)$ & $\mathrm{N} / \mathrm{A}$ & $3.77(1.35,10.69)^{*}$ & $\mathrm{~N} / \mathrm{A}$ \\
\hline
\end{tabular}

$B I D$ twice daily, $C r I$ credible interval, $N / A$ not applicable, $Q D$ once daily, $Q W$ once weekly

* Statistically significant difference

Table 7 Relative effect sizes for risk of treatment discontinuation due to adverse events

\begin{tabular}{|c|c|c|c|c|}
\hline \multirow[t]{3}{*}{ Regimen } & \multicolumn{4}{|c|}{ Risk of treatment discontinuation due to AEs } \\
\hline & \multicolumn{2}{|l|}{ Fixed effect model } & \multicolumn{2}{|l|}{ Random effects model } \\
\hline & $\begin{array}{l}\text { All vs. placebo } \\
\text { Odds ratio } \\
(95 \% \mathrm{CrI})\end{array}$ & $\begin{array}{l}\text { Exenatide } Q W \text { vs. all } \\
\text { Odds ratio } \\
(95 \% \mathrm{CrI})\end{array}$ & $\begin{array}{l}\text { All vs. placebo } \\
\text { Odds ratio } \\
(95 \% \mathrm{CrI})\end{array}$ & $\begin{array}{l}\text { Exenatide } Q W \text { vs. all } \\
\text { Odds ratio } \\
(95 \% \mathrm{CrI})\end{array}$ \\
\hline Placebo & $\mathrm{N} / \mathrm{A}$ & $12.78(1.82,97.03)^{*}$ & $\mathrm{~N} / \mathrm{A}$ & $13.01(0.46,342.41)$ \\
\hline Exenatide $5 \mu \mathrm{g}$ BID & $2.90(0.64,12.43)$ & $4.41(0.48,43.64)$ & $3.49(0.36,48.96)$ & $3.73(0.07,141.17)$ \\
\hline Lixisenatide $20 \mu \mathrm{g}$ QD & $4.45(2.07,10.79)^{*}$ & $2.87(0.49,18.25)$ & $4.76(1.26,20.84)^{*}$ & $2.73(0.12,51.16)$ \\
\hline Exenatide $10 \mu \mathrm{g}$ BID & $5.91(2.51,15.36)^{*}$ & $2.16(0.34,14.60)$ & $6.97(1.42,52.20)^{*}$ & $1.87(0.05,46.25)$ \\
\hline Liraglutide $1.2 \mathrm{mg}$ QD & $22.20(3.94,134.29)^{*}$ & $0.58(0.16,2.21)$ & $23.17(1.36,474.85)^{*}$ & $0.56(0.04,6.75)$ \\
\hline Liraglutide $1.8 \mathrm{mg}$ QD & $23.88(3.87,157.59)^{*}$ & $0.53(0.13,2.34)$ & $24.68(1.02,675.87)^{*}$ & $0.53(0.03,8.42)$ \\
\hline Dulaglutide $1.5 \mathrm{mg} \mathrm{QW}$ & $23.95(3.41,178.57)^{*}$ & $0.53(0.11,2.69)$ & $24.95(0.63,1187.97)$ & $0.52(0.01,15.53)$ \\
\hline Exenatide $2 \mathrm{mg} \mathrm{QW}$ & $12.78(1.82,97.03)^{*}$ & $\mathrm{~N} / \mathrm{A}$ & $13.01(0.46,342.41)$ & $\mathrm{N} / \mathrm{A}$ \\
\hline
\end{tabular}

$A E$ adverse event, $B I D$ twice daily, $C r I$ credible interval, $N / A$ not applicable, $Q D$ once daily, $Q W$ once weekly

* Statistically significant difference

the first once weekly GLP-1 RA, compared to other existing GLP-1 RAs. Overall, the results of this study suggest that exenatide QW has a similar effectiveness and tolerability profile compared to other members of its class, for the treatment of adults with T2DM inadequately controlled on metformin monotherapy, with some evidence of 
improved HbA1c control over lixisenatide, and, though not significant, trends toward improvement in SBP and reduced risk of nausea against all non-exenatide GLP-1 RAs.

Few differences in efficacy between the GLP-1 RAs, as add-on to metformin, were found. Exenatide QW was significantly better than lixisenatide $20 \mu \mathrm{g}$ QD in reducing HbA1c, and comparable to other GLP-1 RAs for change in HbA1c. Exenatide QW demonstrated a trend towards favorable results in the proportion of patients achieving glycemic target compared to both exenatide BID regimens, liraglutide $1.2 \mathrm{mg}$ QD and lixisenatide $20 \mu \mathrm{g}$ QD, although these comparisons were not statistically significant. Change in weight from baseline was comparable for all GLP-1 RAs. The significant difference between exenatide QW and lixisenatide QD in HbA1c reduction, may be partially explained by the fact that the QW dosing of exenatide provides better glycemic control than lixisenatide, a short-acting agent, which is administered once daily and therefore, does not have an effect over $24 \mathrm{~h}$.

Published NMAs on GLP-1 RAs [18, 39, 40] have reported few differences between individual therapies for the outcomes examined [18, 40]. Scott et al., found no statistically significant differences for glycemic control between exenatide QW and liraglutide (1.2 and $1.8 \mathrm{mg}$ ) [18]. A recent NMA, presented as a poster, did report that exenatide QW was associated with a greater reduction in HbA1c compared to dulaglutide $1.5 \mathrm{mg}$ QW in the add-on to metformin network, but differences were not statistically significant [39]. In the current study, however, results indicated that exenatide QW was significantly better than lixisenatide $20 \mu \mathrm{g}$ QD in reducing $\mathrm{HbA1c}$, and comparable to other GLP-1 RAs for change in HbA1c. Another NMA [40] reported that exenatide QW, exenatide $10 \mathrm{mg}$ BID, and liraglutide $1.8 \mathrm{mg}$ QD ranked as the top three agents in terms of weight reduction compared to traditional hypoglycemic agents. In the present NMA, overall change in weight was comparable across all GLP-1 RAs. However, it is important to note that the current study relied upon a different evidence base than previous NMAs, with study duration restricted to $24 \pm 6$ weeks and the inclusion of any GLP-1 RA at licensed doses.

Based on direct head-to-head trials, researchers have reported significant differences between some GLP-1 RAs. In particular, in the DURATION-1 and DURATION-5 trials, exenatide QW was found to have superior efficacy in HbA1c reduction compared to exenatide BID $[8,9]$. In the DURATION-6 trial, the reduction in HbA1c was significantly greater with liraglutide $1.8 \mathrm{mg}$ QD treatment compared to exenatide QW (treatment difference for exenatide minus liraglutide was $0.21 \%$, 95\% CI 0.08-0.33) [10]. Yet, these trials were not included in the present NMA as patients in these trials were on a variety of oral antihyperglycemic agents prior to study entry and continued these throughout the trial, suggesting likely differences in disease severity compared to a population largely on metformin monotherapy.

Real-world evidence of the clinical effectiveness of GLP-1 RAs has been provided by retrospective studies [11-13]. For change in HbA1c from baseline, the efficacy has been reported to be comparable between liraglutide QD and exenatide QW [13], as well as liraglutide QD and exenatide BID [11]. Results of the current NMA also found no differences in HbA1c change between liraglutide QD and exenatide QW. Although HbA1c change between liraglutide QD and exenatide BID was not directly compared, point estimates were similar, particularly for liraglutide $1.2 \mathrm{mg}$ QD and exenatide $10 \mu \mathrm{g}$ BID. One study has 
reported liraglutide to be more efficacious than exenatide BID in reducing HbA1c [12]. However, these studies rely upon the availability of data in medical databases and thus by their study design, may inherently be subject to confounding and bias that is absent from RCTs.

Previous trials have reported that exenatide QW was associated with less frequent mild-to-moderate nausea compared to exenatide BID [8, 9, 41]. In addition, exenatide QW has been previously reported to be associated with fewer treatment discontinuations due to adverse events compared to liraglutide $1.8 \mathrm{mg}$ QD [10]. These findings are in line with the design of exenatide QW, which was developed to provide better tolerability given its gradual titration [42]. However, results in the current study indicated that exenatide QW was comparable to other GLP-1 RAs in the network for both nausea and treatment discontinuation due to AEs. The lack of any significant differences in these results was likely due to the limited evidence base and the low frequency of discontinuation due to AEs in the included trials. Yet, a recent pooled analysis of eight RCTs reported a similar safety and tolerability profile for exenatide QW compared to exenatide BID and liraglutide QD [43]. Results in the current NMA indicated a higher risk of nausea and treatment discontinuation due to AEs with exenatide QW compared to exenatide $5 \mu \mathrm{g}$ BID, although these differences were not statistically significant.

\section{Strengths and Limitations}

A major strength of this study was the comparison of exenatide QW to GLP-1 RAs (albiglutide $30 \mathrm{mg}$ QW, dulaglutide $1.5 \mathrm{mg} \mathrm{QW}$, exenatide $5 \mu \mathrm{g}$ and $10 \mu \mathrm{g}$ BID, liraglutide $1.2 \mathrm{mg}$ and $1.8 \mathrm{mg}$ QD, and lixisenatide $20 \mu \mathrm{g}$ QD) approved for use in the US and/or Europe that has not been investigated in RCTs. In addition, the current study included an examination of several efficacy and tolerability outcomes. Another key strength is the strict inclusion criteria developed for the study. Eligible RCTs were required to include at least $80 \%$ of patients who had failed metformin monotherapy prior to study entry, and received a GLP-1 RA as add-on to metformin during the trial. To minimize heterogeneity in the network, there were several trials that did not meet these criteria; in particular, eight exenatide QW trials [8-10, 44-48] did not meet these criteria and were therefore excluded from the NMA. In fact, this stringent inclusion/exclusion criteria may have led to the exclusion of treatments that may have formed indirect comparisons to the treatments of interest which could have influenced the results. However, these higher order indirect comparisons would also have contributed less weight to the analysis [49].

There are several potential limitations of the analysis. First, baseline characteristics such as gender and ethnicity were not extracted, and there may be potential differences in the patient population based on these characteristics. However, it is unlikely that such characteristics would result in differences in clinical outcomes examined in this study. Second, physical activity and diet are often not reported in the publications and the impact of those components of care cannot be investigated. Third, there are several methodological differences among the trials including incorporation of double-blinded design and titration schedules. Fourth, the sparse network of evidence informing the analyses led to considerable uncertainty around estimates of between-study variance for all endpoints under the RE models (14 trials informing 16 comparisons). The limited 
evidence base was particularly evident for SBP. Finally, aggregate, study-level summaries provided estimates for inclusion in the analysis, and are subject to ecological bias. The alternative would be to use individual patient-level data, which were not available.

\section{CONCLUSION}

Overall, the GLP-1 RA class is effective in controlling hyperglycemia and well-tolerated in patients with T2DM. The results of this NMA demonstrated that, exenatide QW has similar effectiveness and tolerability compared to other GLP-1 RAs, for the treatment of T2DM in adults inadequately controlled on metformin alone. The scientific rigor of the conduct of the SLR and NMA utilized in this study provides confidence in the robustness of the results.

\section{ACKNOWLEDGMENTS}

Sponsorship and article processing charges for this study were funded by AstraZeneca LP (Gaithersburg, Maryland, United States of America). All authors had full access to all of the data in this study and take complete responsibility for the integrity of the data and accuracy of the data analysis. We would like to thank Mary Beth DeYoung (AstraZeneca), David Scott (ICON plc.), and Sarah Goring (ICON plc.) for reviewing the manuscript. We would also like to thank John Wilson (ICON plc.) for his assistance in data analysis, and both Iqra Syed (ICON plc.) and Carita Ng (ICON plc.) for their contribution to data collection for this study. All named authors meet the International Committee of Medical Journal Editors (ICMJE) criteria for authorship for this manuscript, take responsibility for the integrity of the work as a whole, and have given final approval to the version to be published. Partial data from this study were presented at the 2015 International Society for Pharmacoeconomics and Outcomes Research (ISPOR) European Congress in Milan, Italy, in November 2015.

Disclosures. Sheena Kayaniyil was an employee of ICON plc. at the time of manuscript development and/or study conduct. Greta Lozano-Ortega was an employee of ICON plc. at the time of manuscript development and/or study conduct. Heather Bennett was an employee of ICON plc. at the time of manuscript development and/or study conduct. ICON plc. was contracted by AstraZeneca LP to design and conduct the present study. Kristina Johnsson is an AstraZeneca employee and stockholder. Alka Shaunik is an AstraZeneca employee and stockholder. Susan Grandy is an AstraZeneca employee and stockholder. Bernt Kartman is an AstraZeneca employee and stockholder.

Compliance with Ethics Guidelines. This article is based on previously conducted studies, and does not involve any new studies of human or animal subjects performed by any of the authors.

Open Access. This article is distributed under the terms of the Creative Commons Attribution-NonCommercial 4.0 International License (http://creativecommons.org/licenses/ by-nc/4.0/), which permits any noncommercial use, distribution, and reproduction in any medium, provided you give appropriate credit to the original author(s) and the source, provide a link to the Creative Commons license, and indicate if changes were made. 


\section{REFERENCES}

1. Inzucchi SE, Bergenstal RM, Buse JB, Diamant M, Ferrannini E, Nauck M, et al. Management of hyperglycemia in type 2 diabetes, 2015: a patient-centered approach: update to a position statement of the American Diabetes Association and the European Association for the Study of Diabetes. Diabetes Care. 2015;38(1):140-9.

2. DeYoung MB, MacConell L, Sarin V, Trautmann M, Herbert P. Encapsulation of exenatide in poly-(D, L-lactide-co-glycolide). Diabetes Technol Ther. 2011;13(11):1145-54.

3. Gupta V. Glucagon-like peptide-1 analogues: an overview. Indian J Endocrinol Metab. 2013;17(3): 413-21.

4. Lindamood CA, Taylor JR. Emerging new therapies for the treatment of type 2 diabetes mellitus: glucagon-like peptide-1 receptor agonists. Clin Ther. 2015;37(3):483-93.

5. Madsbad S. A review of head-to-head comparisons of GLP-1 receptor agonists. Diabetes Obes Metab. 2015. (Epub ahead of print).

6. Triplitt C, Solis-Herrera C. GLP-1 receptor agonists: practical considerations for clinical practice. Diabetes Educ. 2015;41(1 Suppl):32S-46S.

7. Drucker DJ, Buse JB, Taylor K, Kendall DM, Trautmann M, Zhuang D, et al. Exenatide once weekly versus twice daily for the treatment of type 2 diabetes: a randomised, open-label, non-inferiority study. Lancet. 2008;372(9645):20081004-10.

8. Buse JB, Drucker DJ, Taylor KL, Kim T, Walsh B, Hu $\mathrm{H}$, et al. DURATION-1: exenatide once weekly produces sustained glycemic control and weight loss over 52 weeks. Diabetes Care. 2010;33(6): 1255-61.

9. Blevins T, Pullman J, Malloy J, Yan P, Taylor K, Schulteis C, et al. DURATION-5: exenatide once weekly resulted in greater improvements in glycemic control compared with exenatide twice daily in patients with type 2 diabetes. J Clin Endocrinol Metab. 2011;96(5):1301-10.

10. Buse JB, Nauck M, Forst T, Sheu WHH, Shenouda SK, Heilmann CR, et al. Exenatide once weekly versus liraglutide once daily in patients with type 2 diabetes (DURATION-6): a randomised, open-label study. The Lancet. 2013;381(9861): $117-24$.

11. Miller LA, Burudpakdee C, Zagar A, Bhosle M, Reaney M, Schabert VF, et al. Exenatide BID and liraglutide QD treatment patterns among type 2 diabetes patients in Germany. J Med Econ. 2012;15(4):746-57.

12. Lee WC, Dekoven M, Bouchard J, Massoudi M, Langer J. Improved real-world glycaemic outcomes with liraglutide versus other incretin-based therapies in type 2 diabetes. Diabetes Obes Metab. 2014;16(9):819-26.

13. Saunders W, Nguyen Hiep H, Kalsekar I. Real-world comparative effectiveness of exenatide once weekly and liraglutide in patients with type 2 diabetes mellitus. European Association for the Study of Diabetes Annual Meeting 2014.

14. Caldwell DM, Ades AE, Higgins JP. Simultaneous comparison of multiple treatments: combining direct and indirect evidence. BMJ. 2005;331(7521): 897-900.

15. Dias S, Sutton AJ, Ades AE, Welton NJ. Evidence synthesis for decision making 2: a generalized linear modeling framework for pairwise and network meta-analysis of randomized controlled trials. Med Decis Making. 2013;33(5):607-17.

16. Salanti G, Higgins JP, Ades AE, Ioannidis JP. Evaluation of networks of randomized trials. Stat Methods Med Res. 2008;17(3):279-301.

17. Cochrane Handbook for Systematic Reviews of Interventions Version 5.1.0 [updated March 2011]. The Cochrane Collaboration 2011 [Version 5.1.0 (updated March 2011)]. http://www.cochranehandbook.org. Accessed 28 July 2014.

18. Scott DA, Boye KS, Timlin L, Clark JF, Best JH. A network meta-analysis to compare glycaemic control in patients with type 2 diabetes treated with exenatide once weekly or liraglutide once daily in comparison with insulin glargine, exenatide twice daily or placebo. Diabetes Obes Metab. 2013;15(3):213-23.

19. Vilsboll T, Christensen M, Junker AE, Knop FK, Gluud LL. Effects of glucagon-like peptide-1 receptor agonists on weight loss: systematic review and meta-analyses of randomised controlled trials. BMJ. 2012;344:d7771.

20. Pinelli NR, Hurren KM. Efficacy and safety of long-acting glucagon-like peptide-1 receptor agonists compared with exenatide twice daily and sitagliptin in type 2 diabetes mellitus: a systematic review and meta-analysis. Ann Pharmacother. 2011;45(7-8):850-60.

21. Higgins JP, Altman DG, Gotzsche PC, Juni P, Moher $\mathrm{D}$, Oxman $\mathrm{AD}$, et al. The Cochrane Collaboration's tool for assessing risk of bias in randomised trials. BMJ. 2011;343:d5928. 
22. Lunn DJ, Thomas A, Best N. Spiegelhalter. WinBUGS-A Bayesian modelling framework: concepts, structure, and extensibility. Stat Comput. 2000;10(4):325-37.

23. Dias S, Welton NJ, Sutton AJ, Ades A. NICE DSU Technical Support Document 2: a generalized linear modelling framework for pairwise and network meta-analysis of randomised controlled trials. Report by the Decision Support Unit. 2011.

24. Dias S, Welton NC, Caldwell DM, Ades AE. Checking consistency in mixed treatment comparison meta-analysis. Stats Med. 2010;29:932-44.

25. Ahren B, Dimas AL, Miossec P, Saubadu S, Aronson R. Efficacy and safety of lixisenatide once-daily morning or evening injections in type 2 diabetes inadequately controlled on metformin (GetGoal-M). Diabetes Care. 2013;36(9):2543-50.

26. Ahren B, Johnson SL, Stewart M, Cirkel DT, Yang F, Perry C, et al. HARMONY 3: 104-week randomized, double-blind, placebo- and active-controlled trial assessing the efficacy and safety of albiglutide compared with placebo, sitagliptin, and glimepiride in patients with type 2 diabetes taking metformin. Diabetes Care. 2014;37(8):2141-8.

27. Bergenstal RM, Wysham C, Macconell L, Malloy J, Walsh B, Yan P, et al. Efficacy and safety of exenatide once weekly versus sitagliptin or pioglitazone as an adjunct to metformin for treatment of type 2 diabetes (DURATION-2): a randomised trial. Lancet. 2010;376(9739): 431-9.

28. Bolli GB, Munteanu M, Dotsenko S, Niemoeller E, Boka G, Wu Y, et al. Efficacy and safety of lixisenatide once daily vs. placebo in people with Type 2 diabetes insufficiently controlled on metformin (GetGoal-F1). Diabet Med. 2014;31(2):176-84.

29. Charbonnel B, Steinberg H, Eymard E, Xu L, Thakkar P, Prabhu V, et al. Efficacy and safety over 26 weeks of an oral treatment strategy including sitagliptin compared with an injectable treatment strategy with liraglutide in patients with type 2 diabetes mellitus inadequately controlled on metformin: a randomised clinical trial. Diabetologia. 2013;56(7):1503-11.

30. DeFronzo RA, Ratner RE, Han J, Kim DD, Fineman MS, Baron AD. Effects of exenatide (exendin-4) on glycemic control and weight over 30 weeks in metformin-treated patients with type 2 . Diabetes Care. 2005;28(5):1092-100.

31. DeFronzo RA, Triplitt C, Qu Y, Lewis MS, Maggs D, Glass LC. Effects of exenatide plus rosiglitazone on beta-cell function and insulin sensitivity in subjects with type 2 diabetes on metformin. Diabetes Care. 2010;33(5):951-7.

32. Derosa G, Maffioli P, Salvadeo SAT, Ferrari I, Ragonesi PD, Querci F, et al. Exenatide versus glibenclamide in patients with diabetes. Diabetes Technol Ther. 2010;12(3):01.

33. Derosa G, Putignano P, Bossi AC, Bonaventura A, Querci F, Franzetti IG, et al. Exenatide or glimepiride added to metformin on metabolic control and on insulin resistance in type 2 diabetic patients. Eur J Pharmacol. 2011;666(1-3):251-6.

34. Dungan KM, Povedano ST, Forst T, Gonzalez JG, Atisso C, Sealls W, et al. Once-weekly dulaglutide versus once-daily liraglutide in metformin-treated patients with type 2 diabetes (AWARD-6): a randomised, open-label, phase 3, non-inferiority trial. Lancet. 2014;384(9951):1349-57.

35. Gallwitz B, Bohmer M, Segiet T, Molle A, Milek K, Becker $B$, et al. Exenatide twice daily versus premixed insulin aspart 70/30 in metformin-treated patients with type 2 diabetes: a randomized 26-week study on glycemic control and hypoglycemia. Diabetes Care. 2011;34(3):604-6.

36. Pratley RE, Nauck M, Bailey T, Montanya E, Cuddihy R, Filetti $S$, et al. Liraglutide versus sitagliptin for patients with type 2 diabetes who did not have adequate glycaemic control with metformin: a 26-week, randomised, parallel-group, open-label trial. Lancet. 2010;375(9724):1447-56.

37. Rosenstock J, Raccah D, Koranyi L, Maffei L, Boka $G$, Miossec P, et al. Efficacy and safety of lixisenatide once daily versus exenatide twice daily in type 2 diabetes inadequately controlled on metformin: a 24-week, randomized, open-label, active-controlled study (GetGoal-X). Diabetes Care. 2013;36(10):2945-51.

38. Van GL, Souhami E, Zhou T, Aronson R. Efficacy and safety of the glucagon-like peptide-1 receptor agonist lixisenatide versus the dipeptidyl peptidase-4 inhibitor sitagliptin in young ( $<50$ years) obese patients with type 2 diabetes mellitus. J Cli Transl Endocrinol. 2014;1(2):31-7.

39. Padhiar A, Thompson JC, Eaton JN, Hawkins NS, Norrbacka K, Reaney $M$, et al. A network meta-analysis to compare once weekly dulaglutide versus other GLP-1 receptor agonists in patients with type 2 diabetes. European Association for the Study of Diabetes Annual Meeting 2014.

40. Sun F, Chai S, Li L, Yu K, Yang Z, Wu S, et al. Effects of glucagon-like peptide-1 receptor agonists on weight loss in patients with type 2 diabetes: a systematic review and network meta-analysis. J Diabetes Res. 2015;2015:157201. 
41. Ridge T, Moretto T, MacConell L, Pencek R, Han J, Schulteis $\mathrm{C}$, et al. Comparison of safety and tolerability with continuous (exenatide once weekly) or intermittent (exenatide twice daily) GLP-1 receptor agonism in patients with type 2 diabetes. Diabetes Obes Metab. 2012;14(12):1097-103.

42. Fineman MS, Shen LZ, Taylor K, Kim DD, Baron AD. Effectiveness of progressive dose-escalation of exenatide (exendin-4) in reducing dose-limiting side effects in subjects with type 2 diabetes. Diabetes Metab Res Rev. 2004;20(5):411-7.

43. MacConell L, Gurney K, Malloy J, Zhou M, Kolterman O. Safety and tolerability of exenatide once weekly in patients with type 2 diabetes: an integrated analysis of 4.328 patients. Diabetes Metab Syndr Obes. 2015;8:241-53.

44. Inagaki N, Atsumi $\mathrm{Y}$, Oura $\mathrm{T}$, Saito $\mathrm{H}$, Imaoka T. Efficacy and safety profile of exenatide once weekly compared with insulin once daily in Japanese patients with type 2 diabetes treated with oral antidiabetes $\operatorname{drug}(\mathrm{s})$ : results from a 26-week, randomized, open-label, parallel-group, multicenter, noninferiority study. Clin Ther. 2012;34(9):1892-908.

45. Davies M, Heller S, Sreenan S, Sapin H, Adetunji O, Tahbaz A, et al. Once-weekly exenatide versus once- or twice-daily insulin detemir: randomized, open-label, clinical trial of efficacy and safety in patients with type 2 diabetes treated with metformin alone or in combination with sulfonylureas. Diabetes Care. 2013;36(5):1368-76.

46. Diamant M, Van GL, Guerci B, Stranks S, Han J, Malloy J, et al. Exenatide once weekly versus insulin glargine for type 2 diabetes (DURATION-3): 3-year results of an open-label randomised trial. Lancet Diabetes Endocrinol. 2014;2(6):464-73.

47. Drucker DJ, Buse JB, Taylor K, Kendall DM, Trautmann M, Zhuang D, et al. Exenatide once weekly versus twice daily for the treatment of type 2 diabetes: a randomised, open-label, non-inferiority study. Lancet. 2008;372(9645):1240-50.

48. Ji L, Onishi Y, Ahn CW, Agarwal P, Chou CW, Haber $\mathrm{H}$, et al. Efficacy and safety of exenatide once-weekly vs exenatide twice-daily in Asian patients with type 2 diabetes mellitus. J Diabetes Investig. 2013;4(1):53-61.

49. Hawkins N, Scott DA, Woods B. How far do you go? Efficient searching for indirect evidence. Med Decis Making. 2009;29(3):273-81. 